\title{
Midtrimester amniyotik sivı leptin ve insülin düzeyleri ile gestasyonel diabetes mellitus ilişkisi
}

\section{Midtrimester amniotic fluid leptin and insulin levels and their relation with gestational diabetes mellitus}

\author{
Ahter Tanay Tayyar*, Ahmet Tayyar, Ümmühan Abdülrezzak, Mustafa Kula, \\ Mehmet Tayyar
}

Kadın Hastalıkları ve Doğum Anabilim Dalı (Dr. A. T. Tayyar, Prof. Dr. M. Tayyar), Nükleer Tıp Anabilim Dalı (Yrd. Doç. Dr. Ü. Abdülrezzak, Prof. Dr. M. Kula), Erciyes Üniversitesi Tıp Fakültesi TR-38039 Kayseri, Kadın Hastalıkları ve Doğum Kliniği (Dr. A. Tayyar), Niğde Doğan Baran Hastanesi TR-51100 Niğde

\section{Özet}

Amaç. $\mathrm{Bu}$ çalışmanın amacı midtrimester amniyotik sıvıda leptin ve insülin düzeylerini inceleyerek bunların daha sonraki dönemde gestasyonel diabetes mellitus gelişen olguları tahmin etmede faydalı olup olamayacağını araştırmaktır. Yöntem. Genetik amniyosentezle 16-20 haftalık gebelerden alınan amniyotik sıvı örneklerinde leptin ve insülin düzeylerini araştırdık. Prospektif takiplerde gestasyonel diabetes mellitusta gelişen ve sağlıklı gebelik sürdüren hastaları kaydettik. Bulgular. Gestasyonel diabetes mellitus gelişen grupta amniyotik sıvı leptin $(17,3 \mathrm{ng} / \mathrm{mL})$ ve insülin $(3,4 \mathrm{ng} / \mathrm{mL})$ düzeyleri kontrol grubunun amniyotik sıv1 leptin $(10,1 \mathrm{ng} / \mathrm{mL})$ ile amniyotik sıv1 insülin $(1,7 \mathrm{ng} / \mathrm{dL})$ düzeylerine göre istatistiksel olarak yüksek bulunmuştur. Sonuç. Amniyotik sıvı'da henüz gestasyonel diabetes mellitus bulguları ortaya çıkmadan leptin ve insülin düzeylerinin yüksek bulunması bu proteinlerin gestasyonel diabetes mellitusu önceden tahmin etmede kullanılabileceği kanısını vermektedir.

Anahtar sözcükler: Amniyotik sıvı, leptin, insulin

\begin{abstract}
Aim. The aim of this study is to investigate whether amniotic fluid leptin and insulin levels can be used for prediction of for prediction of gestational diabetes mellitus or not. Methods. The levels of leptin and insulin were measured in the samples of amniotic fluid which were obtained at 16-20 weeks of pregnancy during genetic amniocentesis. We recorded the patients who developed gestational diabetes mellitus and who had healthy gestation. Results. Amniotic fluid leptin (17.3 $\mathrm{ng} / \mathrm{mL})$ and insulin $(3.4 \mathrm{ng} / \mathrm{mL})$ levels were significantly increased in gestational diabetes mellitus group as compared to control group's amniotic fluid leptin $(10.1 \mathrm{ng} / \mathrm{mL})$ and amniotic fluid insülin $(1.7 \mathrm{mg} / \mathrm{mL})$ levels. Conclusion. Increased levels of amniotic fluid leptin and insulin levels before gestational diabetes mellitus symptoms gives the idea that these proteins can be used as predictors for gestational diabetes mellitus.
\end{abstract}

Keywords: Amniotic fluid, leptin, insulin

Geliş tarihi/Received: 19 Aralık 2011; Kabul tarihi/Accepted: 11 Nisan 2012

*İletişim adresi:

Dr. Ahter Tanay Tayyar, Kadın Doğum Hastalıkları ve Doğum Anabilim Dalı, Erciyes Üniversitesi Tıp Fakültesi, TR-38039 Kayseri. E-posta: drahtertayyar@ yahoo.com

\section{Giriş}

Gestasyonel diabetes mellitus (GDM) gebelik esnasında hiperglisemi ortaya çıkması ve artan glukozun fetusa geçip onun gelişimini etkilemesiyle karakterizedir. Fetusun \%50-80 glukoz ihtiyacı maternal kordon vasıtasıyla karşılanırken, \%10-15'lik kısmı ise amniyotik 
sıvı (AS) yutmasıyla sağlanır [1, 2]. GDM fetusu olumsuz yönde etkileyebilmektedir. GDM AS'deki albümine irreverzible oksidatif hasar verir ve laktikasidemi ve fetal hipoksiye sebep olabilir. Ayrıca ketogenezde değişim ve beta hidrosibutirat konsantrasyonunda artışa neden olur. Sonuçta glukoneogenez artar, ürik asit artar ve hipoksiye sebep olabilir [3-7]. İnsülin pankreasta beta hücrelerden salgilanan bir hormondur ve kandan glukozun hücreye alınmasını sağlar. Fetusta insülin salgısı 11. haftada başlamaktadır ve diabetli gebelerde fetal insülinin arttığı gösterilmiştir. Ayrıca bu artışın glukoz düzeyindeki artışla parelellik gösterdiği de saptanmıştır [8]. Leptin sitokinlere benzeyen, 167 aminoasit içeren protein yapısında hormondur. Gebelikte maternal düzeyi midtrimester sonuna kadar artmakta daha sonra doğuma kadar azalmaktadır. Enerji metabolizmasındaki düzenleyici rolü nedeni ile leptin gebelik ve laktasyon süresince maternal adaptasyonda rol almaktadır. İnsülin ise leptinin bu fonksiyonları üzerinde etkilidir. GDM olgularında kord leptin düzeyide yüksektir. AS'de ise sağl1klı gebelerde midtrimester leptin düzeyi terme göre daha fazla bulunmuştur [8$11]$.

Biz bu çalışmada midtrimester AS leptin ve insülin düzeylerini inceleyerek bunların daha sonraki süreçte GDM gelişen olguları tahmin etmede faydalı olup olamayacağını araştırmak istedik.

\section{Gereç ve yöntem}

Araştırmamız 1 Ekim 2009-Mayıs 2010 tarihleri arasında Erciyes Üniversitesi Tıp Fakültesi Kadın Hastalıkları ve Doğum Anabilim Dalı'nda genetik nedenlerle amniyosentez yapılan 16-20 haftalık gebelerde gerçekleştirildi. $\mathrm{Bu}$ olgularda amniyosentez endikasyonları kombine test, üçlü test ve dörtlü testte saptanan risklerdir. Gebelik takibinde saptanan fetal kayıp, erken membran rüptürü, preeklampsi, anormal karyotip durumlarında olgular çalışma kapsamından çıkartıldı. Erciyes Üniversitesi Etik Kurulu'nun onayından sonra çalışmaya alınan hastalardan izin alındı. Prospektif olarak takip edilen gebelerde GDM gelişen olgulardan çalışma grubu (n:12) ve komplikasyonsuz doğum yapanlardan kontrol grubu (n:46) oluşturuldu. GDM tanısı önce 50 gr'lik postprandial glukoz testi ve ardından yapılan 3 saatlik 100 gr'lık oral glukoz tolerans testi ile konuldu. Alınan AS'den numune alınarak $-70^{\circ} \mathrm{C}$ 'de saklandı. Leptin düzeyi radioimmunoassay yöntemi ile Leptin-Ria-CT (DIA source Immuno Assays S.A. , Belçika) kiti kullanılarak, insülin düzeyi INS-Irma (DIA source ImmunoAssays S.A. , Belçika) kiti kullanılarak ölçüldü.

İstatistiksel incelemelerde parite ve cinsiyet karşılaştırılması Ki kare testiyle diğer parametrelerin kıyaslanması ise Mann- Whitney U testi kullanılarak yapıldı. P değeri 0,05 olarak belirlendi. İstatistik, Statistical Package for the Social Sciences (SPSS) for Windows (12.0 version) programında yapıldı.

\section{Bulgular}

Araştırmamızda yaş, nulliparite, amniyosentez yapıldığında gebelik haftası, kız fetus oranı, doğum haftası yönünden GDM ve kontrol grupları karşılaştırıldığında istatistiksel olarak farklılık saptanmamıştır. Ancak doğum ağırlığı GDM grubunda yüksek bulunmuştur. (Tablo 1)

Tablo 1. Çalış̧ma gruplarının bazı özellikleri.

\begin{tabular}{lllc}
\hline & $\begin{array}{c}\text { GDM grubu } \\
\mathbf{n : 1 2}\end{array}$ & $\begin{array}{c}\text { Kontrol grubu } \\
\mathbf{n : 4 6}\end{array}$ & p \\
\hline Yaş (yıl) & $37,2 \pm 4,2$ & $36,1 \pm 3,8$ & $>0,05$ \\
Nulliparite (\%) & 16,6 & 17,3 & $>0,05$ \\
Amniyosentez yapıldığında gebelik haftası $17,2 \pm 0,9$ & $18,4 \pm 1,1$ & $>0,05$ \\
Kız fetus (\%) & 50 & 47,8 & $>0,05$ \\
Doğum haftası & $37,6 \pm 2,1$ & $38,2 \pm 2,2$ & $>0,05$ \\
Doğum ağırlığ1 (gr) & $3750 \pm 480$ & $3220 \pm 340$ & $<0,05$ \\
\hline GDM: Gestasyonel diabetes mellitus & & & \\
\hline
\end{tabular}


Her iki grupta AS leptin ve insülin düzeyleri karşılaştırıldığında ise GDM grubunda istatistiksel olarak belirgin yükseklik bulunmuştur (Tablo 2).

Tablo 2. Gestasyonel diabetes mellitus ve kontrol gruplarında amniyotik sıvı leptin ve insülin düzeyleri.

\begin{tabular}{|c|c|c|c|}
\hline & $\begin{array}{c}\text { GDM grubu } \\
\text { n: } 12\end{array}$ & $\begin{array}{c}\text { Kontrol grubu } \\
\text { n: } 46\end{array}$ & $\mathbf{p}$ \\
\hline AS leptin (ng/mL) & $17,3 \pm 2,9$ & $10,1 \pm 1,9$ & $<0,05$ \\
\hline AS insülin (mU/mL) & $3,4 \pm 1,5$ & $1,7 \pm 0,9$ & $<0,05$ \\
\hline
\end{tabular}

\section{Tartışma}

Çalışmamızda GDM olan olguların yaş ortalaması 37,2 idi (Tablo 1). AS'de insülin düzeyini araştıran Tisi ve ark. [10]'nın araştırmasında maternal yaş ortalaması 37,8 Carpenter ve ark. [8]'nın çalışmasında 38 idi. AS'de leptin ve insülin düzeylerini araştıran D' Anna ve ark. [12]'nın maternal yaş ortalaması 29,4'dü. Maternal yaş farklılıklarının amniyosentez endikasyonlarındaki değişkenlikten kaynaklandığ kanısındayız. GDM'li olgularımızın nulliparite oranı \%16,6 idi (Tablo1). Konuyla ilgili benzer çalışmalarda bu oran bildirilmemiştir. Paritenin AS leptin ve insülin düzeylerine bilinen bir etkisi bulunmamaktadır. Araştırmamızda GDM olgularında amniyosentez yapıldığında gebelik haftası ortalama 17,2 olarak bulunmuştur (Tablo 1). Ortalama gebelik haftası Tisi ve ark. [10]'nın çalışmasında 15,3, Carpenter ve ark. [8]'nın araştırmasında16, D' Anna ve ark. [12]'nın çalışmasında 15,9 olarak saptanmıştır, bu bulgular bizimki ile benzerlik göstermektedir. GDM olan olgularımızda kız fetus oranı \%50 idi (Tablo 1). Bu oran D'Anna ve ark. [12]'nın araştırmasında \%53 olarak bulunmuştur. Çalışmamızda GDM olgularının doğum haftası ortalama 37,6 olarak bulunmuştur (Tablo 1). Bu bulgu D'Anna ve ark. [12]'nın araştırmasında 38,4, Tisi ve ark. [10]'nın çalışmasında 39 olarak saptanmıştır. Bu sonuçlar bizim araştırmamızda saptadığımız ortalama doğum haftası ile benzerlik göstermektedir. GDM olgularımızın doğum ağırlığı 3750 gr'dır. (Tablo 1) ve kontrol grubuna göre istatistiksel olarak yüksek bulunmuştur. GDM olgularında doğum ağırlıklarının ortalamanın üzerinde olması beklenen bulgudur. Ortalama doğum ağırlığını D'Anna ve ark. [12] 3931 gr, Tisi ve ark. [10] ise 3581 gr olarak bildirmişlerdir. Bu bulgular bizim sonuçlarımızla uyumlu bulunmuştur. AS'deki insülinin fetal kaynaklı olduğu bilinmektedir. 16-20. haftalarda fetal pankreasta insülin salgısının GDM'li hastalarda arttığı gösterilmiştir. Kronik insülin uygulaması leptin salgısını artırmaktadır ve diabetik kadınların plasentasında fazla miktarda saptanmıştır [13, 14]. Midtrimesterdeki leptin sentezinin fetal gelişim için gerekli olduğu sanılmaktadır. Ancak fetal ağırlıkla AS leptin düzeyi arası ilişki tartışmalıdır [15, 16]. Diğer yandan cinsiyetin AS leptin düzeyine etkili olduğu, kızlarda daha yüksek düzey bulunduğu rapor edilmiştir [16]. Çalışmamızda GDM ve kontrol gruplarında cinsiyet dağılımı dengeli saptanmıştır. Midtrimestere kadar AS'nin temel kaynağ 1 fetus değildir. 20. haftaya kadar fetal idrar AS'nin major kısmını oluşturmaz. Bu haftaya kadar alınan AS'nin büyük kısmı plasental kaynaklıdır. Ayrıca gebeliğin 14-17. haftasındaki AS leptin düzeyi termdeki seviyeden yüksektir ve maternal leptin ile paralellik göstermez. Bu bilgiler bize midtrimesterde AS'deki leptinin plasentadan kaynaklandığını göstermektedir [2, 9, 12]. Araştırmamızda GDM olgularında AS leptin ve insülin düzeyleri kontrol grubuna göre yüksek bulunmuştur. D’ Anna ve ark. [12] yaptıkları çalışmada benzer bulgu elde etmişlerdir.

Sonuç olarak, GDM olgularında midtrimester AS leptin ve insülin düzeylerinin yüksek olması bize bu incelemenin GDM' yi önceden tahmin etmede kullanılabileceği kanısını vermektedir. Ancak bu konuda daha geniş serilerde araştırmanın yapılması ve cut-off sınırlarının belirlenmesi gerektiği de bir gerçektir. Diğer yandan midtrimester AS leptin 
düzeyinin preeklampsi gelişen hastalarda da yüksek bulunması nedeniyle insülin ile birlikte değerlendirilmesinin daha faydalı olacağı düşüncesini vermektedir.

\section{Kaynaklar}

1. Beardsall K, Diderholm BM, Dunger DB. Insulin and carbohydrate metabolism. Best Pract Res Clin Endocrinol Metab 2008; 22: 41-55.

2. Mulvihill SJ, Stone MM, Debas HT, Fonkalsrud EW. The role of amniotic fluid in fetal nutrition. J Pediat Surg 1985; 20: 668-72.

3. Reece EA. The fetal and maternal consequences of gestational diabetes mellitus. J Matern Fetal Neonatal Med 2010; 23: 199-203.

4. Boisvert MR, Koski KG, Skinner CD. Increased oxidative modifications of amniotic fluid albumin in pregnancies associated with gestational diabetes mellitus. Anal Chem 2010; 82: 1183-7.

5. Taricco E, Radaelli T, Rossi G, Nobile de Santis MS, Bulfamante GP, Avagliano L, Cetin I. Effects of gestational diabetes on fetal oxygen and glucose levels in vivo. BJOG 2009; 116: 1729-35.

6. Pappa KI, Anagnou NP, Salamalekis E, Bikouvarakis S, Maropoulos G, Anogianaki N, Evangeliou A, Koumantakis E. Gestational diabetes exhibits lack of carnitine deficiency despite relatively low carnitine levels and alterations in ketogenesis. J Matern Fetal Neonatal Med 2005; 17: 63-8.

7. Roberts JM, Bodnar LM, Lain KY, Hubel CA, Markovic N, Ness RB, Powers RW. Uric acid is as important as proteinuria in identifying fetal risk in women with gestational hypertension. Hypertension 2005, 46: 1263-9.

8. Carpenter MW, Canick JA, Hogan JW, Shellum C, Somers M, Star JA. Amniotic fluid insulin at 14-20 weeks' gestation: association with later maternal glucose intolerance and birth macrosomia. Diabetes Care 2001; 24: 1259-63.

9. Henson MC, Castracane VD. Leptin in pregnancy: an update. Biol Reprod 2006; 74: 218-29.

10. Tisi DK, Burns DH, Luskey GW, Koski KG. Fetal exposure to altered amniotic fluid glucose, insulin, and insulin-like growth factor-binding protein 1 occurs before screening for gestational diabetes mellitus. Diabetes Care 2011; 1: 139-44.

11. Carpenter MW, Canick JA, Star J, Carr SR, Burke ME, Shahinian K. Fetal hyperinsulinism at 14-20 weeks and subsequent gestational diabetes. Obstet Gynecol 1996; 87: 89-93.

12. D'Anna R, Baviera G, Cannata ML, De Vivo A, Di Benedetto A, Corrado F. Midtrimester amniotic fluid leptin and insulin levels and subsequent gestational diabetes. Gynecol Obstet Invest 2007; 64: 65-8.

13. Star J, Canick JA, Palomaki GE, Carpenter MW, Saller DN Jr, Sung CJ, Tumber MB, Coustan DR. The relationship between second-trimester amniotic fluid insulin and glucose levels and subsequent gestational diabetes. Prenat Diagn 1997; 17: 149-54.

14. Weerasiri T, Riley SF, Sheedy MT, Walstab JE, Wein P. Amniotic fluid insulin values in women with gestational diabetes as a predictor of emerging diabetes mellitus. Aust N Z J Obstet Gynaecol 1993; 33: 358-61.

15. Oktem O, Dedeoğlu N, Oymak Y, Sezen D, Köksal L, Pekin T, Gökaslan H, Kavak ZN. Maternal serum, amniotic fluid and cord leptin levels at term: their correlations with fetal weight. J Perinat Med 2004; 32: 266-71.

16. Cagnacci A, Arangino S, Caretto S, Mazza V, Volpe A. Sexual dimorphism in the levels of amniotic fluid leptin in pregnancies at 16 weeks of gestation: relation to fetal growth. Eur Obstet Gynecol Reprod Biol; 2006; 124: 53-7. 